\title{
Internal space layout and functionality as a major aspect influencing visual analysis for environmental and urban systems
}

\author{
D. Fisher-Gewirtzman \\ Faculty of Architecture and Town Planning, \\ Technion - Israel Institute of Technology, Israel
}

\begin{abstract}
Visibility analyses models and tools predicting human perception have been developed in past years. The Spatial Openness Index, a visibility analysis model defined as the volume of the visible part of a surrounding sphere: the potential of a view and exposure that can indicate the Perceived Density. Visual Openness is one of the main objectives in the development of dense urban areas. This can influence the resident's satisfaction and the real estate value. Visual Exposure, referring to privacy aspects, is also a major aspect influencing the human environmental quality. Visual openness to a view and Visual Exposure expressing visual privacy are two leading, contradicting, but also complementary visual attributes developed as visual analysis for sustainable urban systems. Since different internal functions and activities demand different levels of privacy and can enjoy differently openness to the view, studying the internal space layout and functionality and looking at alternative design in regard to external space analysis is demanded. All models refer to geometrical attributes measured from the external façade towards the surrounding environment and all have an impact on the perceived density and other human environmental comfort, and may contribute to the planning and design process. In this paper, the above models are introduced and a study of the relation between internal space layout and functionality and external visual analysis is suggested.

Keywords: visual analysis, perceived density, spatial openness to the view, visual exposure, environmental quality, sustainability. internal space layout and functionality.
\end{abstract}




\section{Introduction}

Visibility characteristics are an important attribute in high density urban environments and may influence their economic attractiveness. High permeability to a view is one of the main objectives in the development of dense urban areas. It can influence the resident's satisfaction and the real estate value. In addition, Visual Exposure, referring to privacy, is also a major aspect influencing quality of the human environment. The 'Spatial Openness Index' (SOI) is a visibility analysis model and is specified in terms of three-dimensional visual spatial information and defined as the volume of the visible part of a surrounding sphere. SOI measurements in alternative spatial configurations were correlated with the comparative Perceived Density $[17,18]$, thus, the objective measurements indicated a subjective response. Combining these three important factors (The Spatial Openness indicating the Perceived Density, the Openness to the view and the Visual Exposure - referring to visual privacy), a great importance and can support maintaining existing urban environments and developing sustainable urban environments. If designers will acquire knowledge of how to simultaneously preserve low levels of Visual Exposure (in a positive sense as related to privacy) and high levels of visual openness to the view for the residents in an urban environment, the satisfaction of residents with their urban environment will grow $[2,12,32]$. Some additional current methods and automated models for visual analysis are summarized below: An isovist is the area directly visible from any location within the space. Benedikt [7] was the first to introduce the 'isovist' and to develop a set of analytic measurements of isovist properties to be applied in order to achieve quantitative descriptions of spatial environment. A number of researchers have developed measurement methods and tools for automated isovist analysis, amongst them Turner et al [39] that shows how a set of isovist can be used to generate a graph of mutual visibility between locations. As a continuation, they have developed an automated model the Depthmap for visibility graph analysis. Batty [6] describes how a set of isovist forms a visual field whose extent defines different isovist fields of different geometric properties. He suggested a feasible computational scheme for measuring isovist fields and illustrates how they can visualize their spatial and statistical properties by using maps and frequency distributions. Several automated models have been developed in order to examine the 'isovist' in different ways. For example: the 'Spatialist' by Peponis et al [33], and the 'Axman' by Bin Jiang. Several methods show that in different cases visibility is connected to accessibility. For example the Space Syntax method [22] examines the relation between spatial configurations and movement and connects them with the social, cultural and economical functional aspects.

Currently, visibility analysis models for urban systems look at the external space extended from buildings' façades without any concern to the internal space layout. Some analysis models look at façade openings, but only in a very schematic way, and again without concern to the specific function behind the door or window. None regard the internal space layout and functionality. Different internal functions and activities demand different levels of privacy and 
can enjoy differently openness to the view. As an example, the assumption is that in dwellings the living room and bedrooms require different levels of privacy and different levels of openness to external view. Also, offices require less privacy regarding external exposure than dwellings. This is of course, reliant upon human factors such as culture, society, age, gender, etc. Another example is that locating bedrooms in dwellings on the ground floor may suffer from visual exposure but commerce would enjoy greatly the same exposure. Investigating the internal space layout as a parameter influencing the visual analysis models may contribute to broaden and make precise the knowledge in this field and help support a sustainable urban environment.

\subsection{The need for a quantified measure of subjective variables in dense environments}

Researchers have long since distinguished the objective density from the subjective one. Rapoport [34] defined perceived density as the perception of number of people in a given area, and of the available space and of its organization. Stokols [36] distinguished between density as a physical description of people in relation to a given amount of space, and crowding, which he defined as a psychological or subjective experience derived from the recognition that one has less space than desired. What made his work so important was the understanding that crowding is a subjective phenomenon. Subsequently, crowding was defined as a stressful situation that sometimes appears along with high objective density [37]. Several studies tried to identify the relationships between objective density and crowding [11], or residential density. Efforts were directed into identifying the contributing personal and physical factors, as well as the interplay between them. Mitrany [27] demonstrates the complicated relationships that exist between the objective density, the perceived density and the quality of life, where high density is not always correlated with crowding. Well documented, privacy is an important variable in maintaining well-being in high-density environments [3]. Privacy from visual intrusion by strangers (from streets, for example) has been found to be important. Furthermore, privacy of neighbors in the same building or in adjacent ones from each other was found to be a salient kind of privacy [27]. Privacy inside the apartment is achieved through the spatial arrangement of the buildings and the distances between buildings. The placement of the buildings should enable an open view from as many windows of each apartment as possible [28]. The results of the study indicated the importance of spatial openness from one's apartment to the view as a physical variable that affect the evaluation of the density made by residents, as well as other physical variables that contribute to privacy at home. Although researchers in the field of environmental psychology has paid a fare amount of attention to the subjective aspects of high density, they still lack the ability to transfer the existing knowledge to quantified tools that planners and architects can use in order to accurately assess the impact of densification on residents. 


\section{Visibility analyses indicating on human perception}

\subsection{The Spatial Openness Index (SOI)}

The SOI - Spatial Openness Index - which can also be described as a 'threedimensional isovist, can explore the three-dimensional visibility and permeability of spatial configurations and enable the ranking of alternative configurations by measuring the volume of the open space. It was the first real attempt to simulate human three dimensional visual perception $[15,17]$. SOI measurements in alternative spatial configurations were correlated with the comparative perceived density [16], thus, the objective measurements indicated a subjective response. The measurements were carried out on alternative abstract configurations in the same volumetric density and the participants responded to virtual images. The SOI measurements have not yet been tested on realistic urban environments, and were not correlated yet with resident's subjective response.

Following, a preliminary automated model, enabling measurement of Spatial Openness for alternative spatial configurations within given constraints, was developed through collaboration between architecture and computer science researchers [15]. This automated SOI model can explore the visibility and permeability of spatial configurations and enables the ranking of alternative spatial configurations as illustrated in figure 3. The results are presented numerically and graphically. The volumes are coloured in accordance to their SOI values.

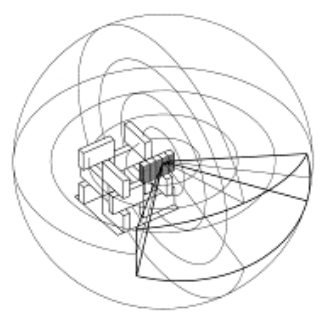

Figure 1: Spatial Openness Index (SOI) defined as the volume of a surrounding sphere, which is visible from a given point of view.
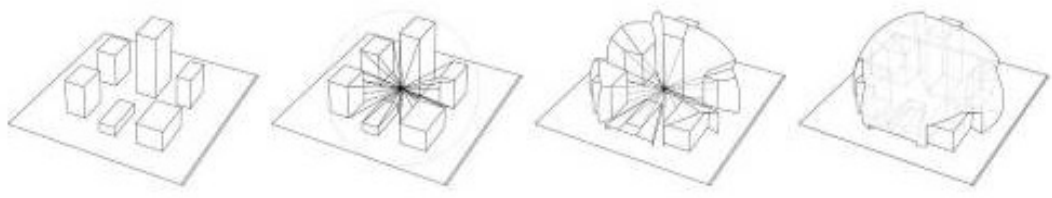

Figure 2: $\quad$ Spatial Openness Index (SOI) for the public spaces is defined as the potential view captured from the viewpoint indicated between the buildings. It is defined as the visible measured volume of space. 

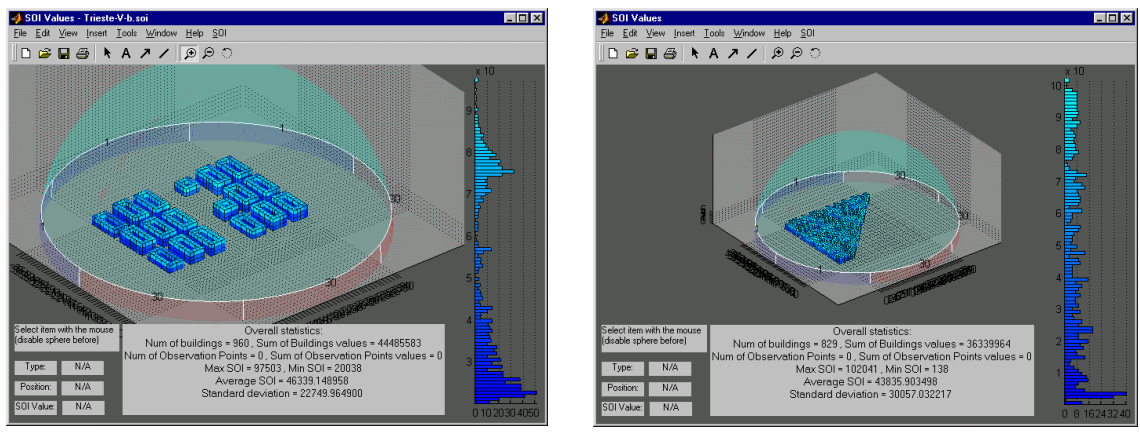

Figure 3: SOI values for two urban configurations: On the left simulating the old city of Trieste, on the right simulating part of the Barceloneta Barcelona, Spain.

\subsection{The visual exposure and visual openness: a complementary approach}

Visual Openness and Visual Exposure may appear to be contradictory terms. Visual Openness would be considered as an advantage, insofar as views are longer and further away, and measured by long distances, while visual exposure is defined and measured by short viewing distances. Visual exposure refers to privacy aspects in the built environment and is defined as the visual penetration into one's privacy as a result of being viewed from the external spaces of other building façades or from public spaces at street level. Most relevant precedent research regarding Visual Exposure has been based on qualitative methods. The concept of 'Visual Exposure' is part of the definition of 'visual privacy [31]. This study focuses on the concept of 'Visual Exposure' only, the visual penetration of one's privacy as a result of being viewed from the external spaces of other building façades or public spaces at street level, as can be geometrically measured. As to Visual Exposure, [4] evaluated environmental and behavioral aspects and argued that 'visual access', the ability to monitor one's surroundings by sight, and Visual Exposure, the probability that one's behavior can be monitored by sight from one's surroundings, are the most fundamental attributes that subsume both environmental and behavioral aspects. These terms enable us to relate to environmental characteristics such as access and exposure as sources for a changing environment. The most dominant attribute found in the literature survey affecting visual exposure is the distance between buildings $[1,10,26]$. However, there is no approach that systematically classifies distances between buildings in relation to visibility. Al-Kodmany [2] and Day [10] argued that the arrangements of buildings of different heights could greatly disturb visual privacy. Asif and Malis, [5] argued that the height and location of facade openings in relation to those in adjacent buildings is critical to visual exposure.

Visual openness to the view is defined as two indices reflecting the measured area of built facades from which the view can be observed and the measured landscape area being viewed: the isovist area [7]. Several researchers have studied visual openness to the view in the urban environment. Gibson [19] 
argued that visual perception does not require information processing and is a direct detection of the visual environment. He argued that reflected light is structured by characteristics of the reflecting surfaces [20]. Lynch [25] was concerned mainly with the image of the environment, and his analysis is primarily based through vision. Cullen [9] argued that the environment is perceived by vision. Visibility has a strong impact also in Thiel's [38] theory. The visual world for Thiel is divided into three-dimensional objects, twodimensional surfaces, and screens that serve as intermediate elements between objects and surfaces. Several researchers argued that access to an open view has strong impact on people's satisfaction from their surrounding urban environment and their willingness to pay for a view. For example: Feitelson [12] and Oh et al [32] found that landscape views had a strong impact on determining housing prices. The most desired view for which people were willing to pay was a river, water view, or green mountains. Kfir [24] found that a view from the dwelling units is essential for residents' satisfaction with their environment in Man-Made Island in Japan. Kaplan and Kaplan [23] argued that one of the components that make an environment restorative is the extent of the view, its richness and coherence. Yoshiyuki et al [40], and Hidetoshi et al [21] pointed out that open areas such as waterfronts adjacent to high-density buildings in Japan increased tenant satisfaction with their living environments.

\section{Objectives}

The objective of this study is to indicate that visibility analysis must take into consideration the internal space layout and functionality otherwise, outcomes may be deceivable. Calculations may be accurate but meaning may be contradicting regarding Environmental quality values, and have various interpretations on perception and quality of space. Indicating high visual permeability to external view may be appreciated greatly from some spaces and unimportant in others. High Visual Exposure may interrupt privacy in private spaces but at the same time, it may indicate high visibility and connectivity desired by public and commercial spaces.

\section{The impact of interior space layout and functionality on visibility analysis}

Existing visual analysis models and tools for environmental and urban systems, aspire to examine external space configuration in variant ways without regarding the content and layout of internal space. Figure 4 illustrates a visual Exposure analysis for dwelling blocks at the Bat-Galim neighborhood, Haifa. The analysis is conducted regarding all openings on facades illustrated in a similar way. There is no reference to apartments' layout within the block and functional distribution within apartments. One of the analysis outcomes was that openings (windows) at ground level gain very high levels of Visual Exposure, meaning there is great penetration to the privacy of the apartments at ground level. At the same time, 


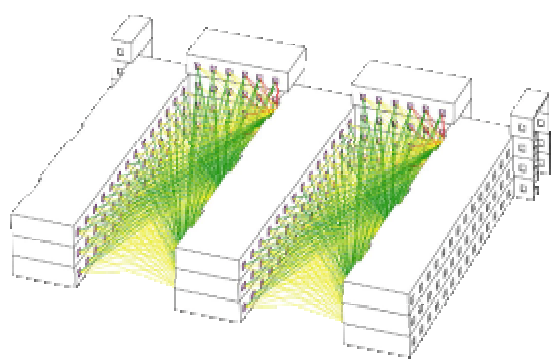

Figure 4: Illustrating visual exposure analysis for dwelling blocks at the BatGalim neighborhood, Haifa. No reference to apartments' layout.

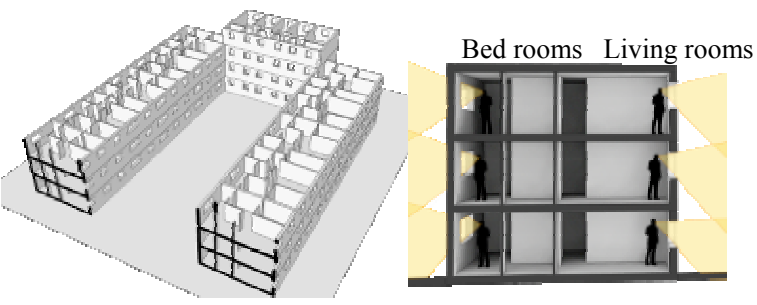

Figure 5: Existing interior space layout and functionality: Repetitive simple one-story apartments. Repetitive levels. No access to the roof. [13, 14].

analysis showed very low Visual Openness to the external view. In case the internal space layout and functionality are similar on all levels, as illustrated in figure 5 , this is a negative out come.

In table 1 it is very obvious that all apartments at street level are visually exposed by passersby, which result all shutters being closed and other view blocking elements. This is blocking the little openness to the view left as illustrated in table 1. Table 2 illustrates better outcomes for Visual Exposure, meaning better visual privacy and at the same time better outcomes for visual openness, meaning dwelling comfort is higher on these built levels. No analysis was conducted for roof level as it is not in use, although from the roof a wonderful view of the Mediterranean Sea is available.

Table 1: Visual exposure and visual openness levels at street level in existing built configuration [35].

\begin{tabular}{|c|c|c|c|}
\hline $\begin{array}{c}\text { Visual Exposure } \\
\text { category }\end{array}$ & $\begin{array}{c}\text { \% openings on } \\
\text { facades }\end{array}$ & $\begin{array}{c}\text { Visual Openness } \\
\text { level }\end{array}$ & $\begin{array}{c}\text { \% openings } \\
\text { on facades }\end{array}$ \\
\hline $\mathrm{X}<10$ & $30 \%$ & Low & $42 \%$ \\
\hline $10<\mathrm{X}<25$ & $70 \%$ & Medium & $37 \%$ \\
\hline $25<\mathrm{X}<50$ & $0 \%$ & High & $21 \%$ \\
\hline
\end{tabular}


Table 2: $\quad$ Visual exposure and visual openness levels on 2-4 floor- levels in existing built configuration [35].

\begin{tabular}{|c|c|c|c|}
\hline $\begin{array}{c}\text { Visual Exposure } \\
\text { category }\end{array}$ & $\begin{array}{c}\text { \% openings on } \\
\text { facades }\end{array}$ & $\begin{array}{c}\text { Visual Openness } \\
\text { level }\end{array}$ & $\begin{array}{c}\text { \% openings } \\
\text { on facades }\end{array}$ \\
\hline $\mathrm{X}<10$ & $8 \%$ & Low & $41 \%$ \\
\hline $10<\mathrm{X}<25$ & $63 \%$ & Medium & $37 \%$ \\
\hline $25<\mathrm{X}<50$ & $29 \%$ & High & $22 \%$ \\
\hline
\end{tabular}

\subsection{Alternative space layout and functionality}

A preliminary study was conducted using the Bat-Galim case study, looking for the impact of variant space layouts regarding the analysis outcomes. Following are illustrated two examples: Figure 6 illustrates the first alternative schematic design: Repetitive narrow vertical apartments. Each apartment provides private entrances at street-level; Roof terraces overlooking the sea view and double-layer protection for private spaces [13]. In this case, entrances at street level do not require Visual Privacy; On the contrary, they demand visibility that would promote homeland security [29, 30]. So, in this case, the high scores for Visual Exposure are contributing to the tenets environmental quality. Roof level is a big potential for openness to the view and functions demanding visual privacy are located on the upper levels and visually protected by layers.

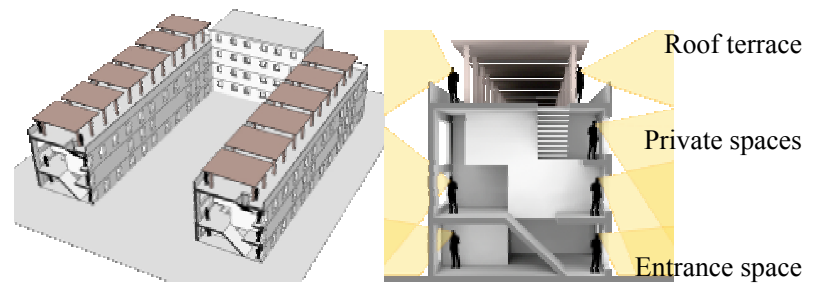

Figure 6: First alternative schematic design: Repetitive vertical apartments. Providing private entrances at street level, roof terraces and doublelayer protection for private spaces $[13,14]$.

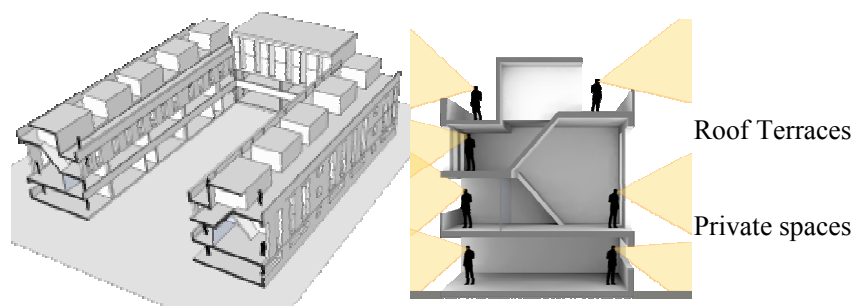

Figure 7: Second alternative schematic design: Repetitive vertical duplex apartments placed on top of commercial ground floor. Private entrances at street level, Roof terraces and a public roof promenade $[13,14]$. 
Figure 8 illustrates the second alternative schematic design: Repetitive vertical duplex apartments placed on top of public and commercial space, together with private entrances to the dwelling apartments. This alternative provides also a roof terraces and a public roof promenade, [13]. In this case street level requires high visibility and accessibility. Roof level provides private and public openness to the view. Functions demanding visual privacy are located on upper levels and have considerable visual protection regarding their privacy and at the same time have visual openness to external view. This alternative would also gain higher scores for the Environmental quality and the impact on quality of life of the residents.

Figure 8 compares the graphic representation for visual openness to the view regarding the existing apartment's layout and in the two alternatives suggesting view from roof terraces. This is just an example for the impact of interior space layout and functionality on visibility analysis

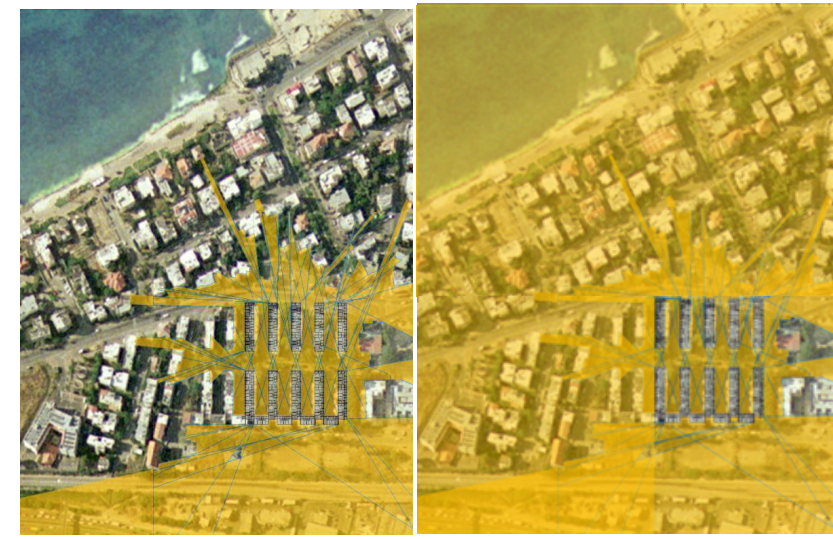

Figure 8: Comparing visual openness. Integrating isovist area from roof terraces as measured at the Bat-Galim neighborhood.

\section{Concluding remarks}

Public and commercial functions demand a high level of visibility and accessibility, therefore locating them at street level, where Visual exposure is high would contribute to the built compound environmental quality. Entrances to vertical dwelling units, located at street level, preferably would need high levels of visual exposure to maintain home-land security, as opposed to bedrooms located on ground floor as in the existing apartments. Private functions, such as bedrooms, located on upper levels of the building, would gain a lower level of visual exposure, meaning a higher level of visual privacy. Utilizing existing roofs as roof terraces would increase the openness to the view and add significantly to the quality and attractiveness of the dwellings.

If comparing the built compounds' existing internal space layout with the two schematically designed variations it is obvious that the analysis outcomes may be 
interpreted differently and that in order to conclude a general level of environmental quality from the variant visual analyses, different weight should be considered regarding the function. To conclude, visibility-analyses would not be precise without relating to the function and internal layout. A thorough study is planed ahead. It is assumed that such a study would contribute greatly to future sustainable planning and design.

\section{References:}

[1] Al-Kodmany K., (1999), Residential visual privacy: Traditional and modern architecture and urban design, Journal of Urban Design, 4 (3), pp. 283-311.

[2] Al-Kodmany, K., (2000), Women's visual privacy in traditional and modern neighborhoods in Damascus, Journal of Architectural and Planning Research, 17 (4), pp.283-303.

[3] Altman, I. (1975) "The Environment and Social Behavior", Monterey, CA: Brooks/Cole.

[4] Archea, J. (1977), The place of architecture factors in behavioral theories of privacy, Journal of Social Issues, 33 (3), pp. 116-137.

[5] Asif S., and Malis N., (1998), High-density neighborhoods - Guidelines for urban design, Ministry of housing, Jerusalem, Israel.

[6] Batty M, 2001, "Exploring isovist fields: space and shape in architectural and urban morphology." Environment and Planning B: Planning and design, vol. 28, pages 123-150.

[7] Benedikt M L, 1979, “ To take hold of space: isovist fields" Environment and Planning B: Planning and Design, vol.6, pages 47-65.

[8] Benson E D, Hansen J L, Schwartz J R, Smersh G T, 1998, "pricing residential Amenities: The value of a view". Journal of Real Estate Finance and Economics, 16:1 55-73.

[9] Cullen, G., (1971), The Concise Townscape, The Architectural Press.

[10] Day L.L., (2000), Choosing a house: The relationship between dwelling type, perception of privacy, and residential satisfaction, Journal of Planning Education and Research, 19 (3), pp. 265-275.

[11] Evans, G. \& Lepore, S.J. (1998). "Chronic Residential Crowding and Children's Well Being: An Ecological Perspective", Paper presented at 24th International Congress of IAAP, San Francisco.

[12] Feitelson E, 1990, "Consumers Preferences and Willingness to Pay For Water Related Residence in Non Urban Setting: A Vignette analysis" Regional studies Vol $26.1 \mathrm{pp}$ 49-68

[13] Fisher-Gewirtzman D. (2009) "The Visual Openness \& Visual Exposure model in regard to internal space layout and functionality. "3 ${ }^{\text {rd }}$ ICA Workshop on Geospatial Analysis and Modeling, Gavle Sweden

[14] Fisher Gewirtzman D. (2008) "Transforming compact apartments in Public Housing blocks built in Israel during the 1950's into contemporary living spaces" IFW Interiors Forum World 2008, Politecnico De Milano 
[15] Fisher-Gewirtzman D. and Wagner I. A., (2006), The 'Spatial Openness Index': an automated model for 3-D visual analysis of Urban Environments, Journal of Architecture and Planning Research, 23 (1), pp. 77-89

[16] Fisher Gewirtzman D., Shach-Pinsly D., Wagner A. I., Burt M., (2005), View Oriented Three Dimensional Visual Analysis Models for the Urban

[17] Fisher Gewirtzman D \& Wagner I, 2003, “ Spatial Openness as a Practical Metric for Evaluating Built-Up Environments" Environment and Planning B: Planning and Design Vol. 30 issue 1 pages 37-49

[18] Fisher Gewirtzman D, Burt M, Tzamir Y, 2003, “ A 3D Method for Comparative Evaluation of Dense Built-up Environments" Environment and Planning B: Planning and Design Vol. 30 issue 4 pages 575-587

[19] Gibson, J. J., (1974), The perception of the visual world, Westport, Conn.: Greenwood Press.

[20] Gibson, J. J., (1979), The ecological approach to visual perception, Boston: Houghton Mifflin.

[21] Hidetoshi, W., Akio, K., Takashi, N., (1995), A study on the relation of resident's evaluation on waterfront area and living environment, Nihon kenchiku Gakkai Keikakukei ronbun hokoku shu = Journal of Architecture Planning and Environmental Engineering, n.2 (468), p.199-206, Feb.

[22] Hillier B, 1996, "Space is the Machine" Cambridge, UK: Cambridge

[23] Kaplan, R., \& Kaplan, S., (1989) The experience of nature: A psychological perspective. New York: Cambridge University Press

[24] Kfir I Z, 2001, "Research on Residential preferences and the view from the dwelling units on man-made islands in Osaka bay" Submitted in Partial fulfilment of the requirements for the degree of Doctor in Engineering, Department of Architecture and Architectural Systems, Graduate School of

[25] Lynch, K., (1960), The Image of the City, Cambridge Mass, MIT Press.

[26] Merry, S., (1987). "Crowding conflict and neighborhood regulation. In : Altman, I. \& Wandersman, A. (Esd). "Neighborhood and Community Environments", New York: Plenum.

[27] Mitrany, M. (2002). "Subjective Housing Density and the Housing Context”, Ph.D. Dissertation, Haifa: Technion, Faculty of Architecture and Town

[28] Mitrany, M. \& Churchman, A. (2004) Positive aspects of Neighborhood High Density. To Tikhnun. (Hebrew, accepted).

[29] Newman O., (1972), Defensible Space: Crime Prevention through Urban Design, Macmillan, New York.

[30] Newman O., (1995), Defensible Space, A New Physical Planning Tool for Urban Revitalization, American Planning Association Journal, 61 (2), pp. 149-155.

[31] Newell, P.B., (1995), Perspectives on Privacy, Journal of Environmental Psychology, 15, pp.87-104.

[32] Oh K. and Lee W., (2002), "Estimating the value of landscape visibility in apartment housing prices", Journal of Architectural and Planning Research, 19 (1), pp. 1-11. 
[33] Peponis J, Winerman J, Rashid M, Bafna S, Hong Kim S, 1998, "Describing Plan Configuration According to the Covisibility of Surfaces." Environment and Planning B: Planning and Design Vol 25 pages 693-708.

[34] Rapoport, A. (1975). "Toward a redefinition of density", Environment and

[35] Shach-Pinsly D., Fisher-Gewirtzman D., Burt M., (2007), "Visual exposure analysis model; a comparative evaluation of three case studies", Urban Design International, 12, pp. 155-168.

[36] Stokols, D. (1972). "A social-psychological model of human crowding phenomena". Journal of the American Institute of Planners, $\underline{38,} 72$ - 83.

[37] Sundstorm, E. (1978). "Crowding as a Sequential Process: Review of Research on the Effects of Population Density on Humans, In Baum", A., \& Epstein, Y. M. (Eds.). "Human Response to Crowding", Hillsdale, New Jersey: Lawrence Erlbaum, pp.32-116.

[38] Thiel P., (1981), Visual awareness and design: an introductory program in conceptual awareness, perceptual sensitivity, and basic design skills, Seattle, Wash.: University of Washington Press.

[39] Turner A, Doxa M, O’Sullivan D, Pen A, 2001, "From isovists to visibility graphs: a methodology for the analysis of architectural space" Environment and Planning B: Planning and Design Vol 28 pages 103-122.

[40] Yoshiyuki, T., Hidetoshi, W., Akio, K., (1997) "A study on effect of urban waterfront area in high density living environment ", Nihon kenchiku Gakkai Keikakukei ronbun hokoku shu = Journal of Architecture Planning and Environmental Engineering, n.4(494), p.277-284,Apr. 